\title{
Congestion Pricing of Urban Street Segments along with MRT Route-The Case Study of Dhaka, Bangladesh
}

\author{
Mohammad Mushfiqul Islam¹, Niloy Saha ${ }^{2 *}$, Md. Sajedur Rahman1, Nasir Uddin Ahmed \\ ${ }^{1}$ Military Institute of Science and Technology, Dhaka, Bangladesh \\ ${ }^{2}$ North Dakota State University, Fargo, ND, USA \\ Email: *niloy.saha@ndsu.edu
}

How to cite this paper: Islam, M.M., Saha, N., Rahman, Md.S. and Ahmed, N.U. (2021) Congestion Pricing of Urban Street Segments along with MRT Route-The Case Study of Dhaka, Bangladesh. Journal of Transportation Technologies, 11, 168-178. https://doi.org/10.4236/jtts.2021.112011

Received: March 10, 2021

Accepted: March 27, 2021

Published: March 30, 2021

Copyright $\odot 2021$ by author(s) and Scientific Research Publishing Inc. This work is licensed under the Creative Commons Attribution International License (CC BY 4.0).

http://creativecommons.org/licenses/by/4.0/

\begin{abstract}
Dhaka, Bangladesh's capital, already has a congestion problem to handle the ever-growing demand for traffic. The usage of private cars cannot be stopped by charging and the town is not encouraged by quality public transport. It is impossible to enforce congestion prices here in line with traditional cordon pricing systems since the region uses unusual land patterns. However, the current project Mass Rapid Transit (MRT) Line 6, which will be built by 2021, provides the prospect of congestion pricing. A price and optimum approach were established for this article. The congestion price is only payable for the segments and is accessible for private cars under this system. Two urban street segments along the MRT route were selected for the study and congestion toll for a private car is estimated for each segment separately. The sum of the toll in monetary terms is determined using certain associated parameters from the discrepancy from the actual Level of Service (LOS) travel time and traffic flow to the desired LOS. The outcome has shown that the price per passenger car is $\$ 0.3-\$ 0.44$. The price is flexible, which means it will vary based on traffic volume. The findings for politicians to enforce congestion pricing are viewed as recommendations.
\end{abstract}

\section{Keywords}

Congestion Price, Urban Street Segment, Level of Service, MRT

\section{Introduction}

Congestion Pricing has been implemented in many developed countries adopting different pricing schemes to impose surcharges for the vehicle users in the 
road network. This results in discouraging passenger vehicles to drive through a particular road segment to reduce congestion. Over the last few decades, London, Stockholm, Singapore, and several cities implemented this scheme and are still running this process to mitigate congestion [1]. European Union measures have been initiated to research, introduce, and assess a large variety of demonstrations and operating programs for congestion pricing [1]. Singapore is the pioneer in this sector where in 1975, congestion pricing was started with AM peak charging $\$ 1.30$, resulting in a $73 \%$ drop of cars entering the restricted zone. Additionally, bus share increased up to $46 \%$ [2]. London started road pricing in 2003, charging 8 pounds which resulted in a 15\% reduction of traffic during charging time, $30 \%$ speed increase, along with a $40 \%$ increase in bus usage [3]. Stockholm started implementing congestion pricing in 2008 with a rate of $\$ 1.33$ resulting in a 50\% reduction in traffic during charging time [4]. Other benefits have been observed such as a reduction in the number of trips, air quality improvement, and revenue generation [5].

However, Dhaka's land-use trend does not lend itself to an especially successful scheme for congestion pricing. While there is ample north-south connectivity, east-west connectivity is lacking. The only viable form of public transit in certain dense urban areas is by bus. Furthermore, buses are not up to the mark or so-called below standard. In this circumstance, a cordon implementation and toll imposing on private cars to allow mass people to utilize public transit will be challenging. The ongoing construction of Mass Rapid Transit Line 6 (metro rail) will be built by the end of 2021 [6]. From looking at the end of plans for Dhaka Mass Transit Company Limited, we may infer that MRT Line- 6 will serve from Uttara to Kamalapur (north-south direction). MRT-6 will be successful public transit if people in the vicinity of the route use this mode instead of the private car. A congestion pricing is necessary to check the benefit of shifting from private car to MRT-6.

Several methods are followed for road pricing such as cordon-based, timebased, distance-based, and congestion-based [7]. Singapore started using Area Licensing Scheme (ALS) in 1975 based on cordon road pricing methodology to discourage the widespread use of private cars inside the Central business district (CBD) area, especially in the morning peak hours to reduce traffic jams [8]. However, the validity of the toll was raised as a question of whether the amount was correct [9] [10].

Moreover, several studies have been attempted in Dhaka city in recent years. Bakkarsiddique et al. (2013) demonstrated a survey-based result to investigate the potential response to congestion cost and found that there is a significant portion of automobile users in Dhaka who are alert to the cost of congestions and are prepared to switch to alternate modes [11]. Khan et al. (2013) estimated traffic congestion cost for this city, which comes up to $\$ 3868$ million annually [12]. But further research is needed on cordon pricing that should be charged during price implementation. Service standards Cordon pricing was also developed based on Dhaka city in past research [7], but pricing calculation requires 
calibration of several parameters based on study area, which is sometimes challenging and time-consuming to conclude. It was necessary to use a formula that provides a similar result to regular cordon pricing calculation considering just a few parameters.

$\mathrm{Li}$ (1999) created a basic model for the best approach to present toll for ALS congestion [8]. This is focused on just the statistics on the number of car owners utilizing the average wage rate and takes recent research on the importance of saving time into account. This formula provides an easy way to test whether congestion toll charging is fair or not. Following the similar pattern later in this paper, a methodology is developed for congestion toll estimation in a developed pricing scheme relating to Level of Service (LOS). The purpose of this study is to show the cost associated with driving passenger cars along the route of MRT-6 so that people are aware of that cost and shift their mode of transport choice to public transit. Several benefits of this study include it is the first-ever study on road pricing that estimates congestion toll relating to LOS and route along MRT-6, and it uses an easy computational method to assess pricing. Two urban street segments selected as "Mirpur 10 Intersection to Agargaon Intersection" and "Agargaon Intersection to Bijoy Sarani" have been identified as the definition of "Urban Street Segments" in the Highway Capacity Manual [13], which are 3.7 kilometers and 1.4 kilometers long accordingly. These two segments would be covered by four metro stations over a median. The reasons for choosing those locations are because of the relatively close office and manufacturing sector, heavy traffic congestion, and air pollution during the morning peak hours (7:30-9:30a.m.).

The rest of the paper is organized as follows. Section 2 describes the case review. Section 3 describes the methodology for the pricing scheme and toll estimation. Data collected from the field survey are analyzed and followed by LOS is determined in Section 4. Congestion tolls are also estimated in this section. Section 5 concludes the study by presenting guidelines to the policymakers.

\section{Case Review}

The Electronic Road Pricing (ERP) framework in Singapore was widely credited with the reduction of traffic congestion and time. The Cordon Price Schemes, which was substituted in 1998 by ERP, was formerly introduced according to the Area Licensing Scheme (ALS). The ALS consisted of a restricted region (RZ) in the city covering the whole CBD and Chinatown's industrial districts and most of the Orchard Road Retail Corridor up to Scotts Road. The initial aim of early ALS was to avoid large usage in early morning peak hours of private cars to alleviate congestion for commuting purposes to the CBD. After more than two decades, the ALS had proved to be quite successful, but some studies have challenged the fairness of the congestion charges. Following this, Li (1999) established a basic model for checking how close the congestion toll of the ALS was to the optimum. Only the overall pay scale of car owners was used based on traffic counts details and facts about the importance of time saves were carried on. The 
"Equation (1)" developed for congestion toll (CT) estimation was as follows.

$$
\left.\mathrm{CT}=\left[\frac{\left(T_{w, \mathrm{non}-\mathrm{ALS}}-T_{w, \mathrm{ALS}}\right) \delta_{w} \omega}{X_{\text {non ALS }}-X_{\mathrm{ALS}}}+\frac{\left(T_{m, \text { non-ALS }}-T_{m, \mathrm{ALS}}\right) \delta_{m} \omega}{X_{\text {non-ALS }}-X_{\mathrm{ALS}}}\right]\right] x
$$

where,

$T=$ time; $\delta$, the value of time as a percentage of average wage rate; $\omega$, average wage rate; $\mathrm{m}$, the moving state of driving; $w$, the waiting state of driving; ALS = the ALS period; non-ALS = the non-ALS period; $x=$ traffic level at any time.

This paper modifies Li's (1999) equation and uses a technique for the calculation of the congestion fee for the vehicle using Level of Service (LOS) later. Although the price framework established in this analysis is not a cordon pricing methodology, the input parameters of the Li research are the same as the input methodology. By the advancement of this article, the reliability of the toll assessment approach is justified.

\section{Methodology}

This pricing scheme can be named Segment Pricing. For describing the methodology first urban street segment "Mirpur 10 Intersection to Agargaon Intersection" is addressed as segment 1 and the second urban street segment "Agargaon Intersection to Bijoy Sarani Intersection" is addressed as segment 2.

Along with both segments, the morning heading is marked in Figure 1 (from Mirpur 10 to Bijoy Sarani). Concerning the pricing for cordons, each section includes an entry point where the gantry may be mounted for charging (Figure 1). Private cars are paid for the section or segments they use during the morning's peak hours (7:30-9:30 AM). The congestion toll for segment 1 must be charged as the first ports travel into the segment. To utilize the second segment, congestion charges must also be charged for segment 2 from the second gantry. If a private car makes a right or left turn after segment 1 access is granted, the next segment would not be paid. Private cars on the other hand can use the congestion fee for segment 2 only from other legs of the intersection of Agargaon (Figure 1). Both access points shall be closed in the morning throughout the peak hours, and those from access points who reached these segments shall join them from segment 1 intersection end of Mirpur 10 (for segment 1) or from segment 2 of the Agargaon intersection (for availing segment 2 ).

From the discussion of section 2 , it can be said that equation 1 is very useful to check the congestion toll where it is already imposed. Irrespective of any pricing scheme Equation (1) can be written as

$$
\mathrm{CT}=\left[\frac{\left(T_{w, \text { non priced }}-T_{w, \text { priced }}\right) \delta_{w} \omega}{X_{\text {non priced }}-X_{\text {priced }}}+\frac{\left(T_{m, \text { non priced }}-T_{m, \text { priced }}\right) \delta_{m} \omega}{X_{\text {non priced }}-X_{\text {priced }}}\right] X
$$

where,

priced $=$ the period considering congestion pricing is in operation; non-priced $=$ the period considering no congestion pricing. The rest of the parameters remain the same. 
Bijoy Saran Intersection
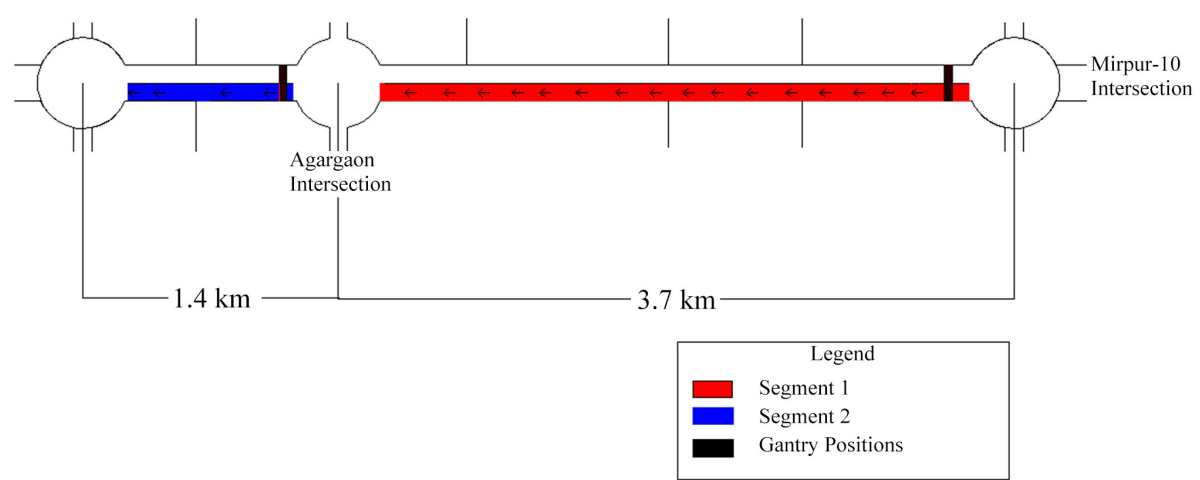

Figure 1. Selected urban street segments.

However, congestion rates cannot be determined by way of "Equation (2)", instead, it is helpful to modify the current rates due to the adjustment of travel time and traffic frequency. Now that we have traced back to the LOS definition, we realize that LOS is a qualitative indicator that demonstrates travel efficiency in an urban road section. Better LOS implies improved speed and thus a lower time of drive and therefore a lower time of waiting at the intersection. From field data, one can conveniently find a complete travel time at the moving state and time at the intersections in the current condition. Applying "Urban street segments", "signalized intersections" of HCM (2016) respectively, average speeds of traffic and waiting time at the intersection that correlates to an ideal LOS (desired LOS better than existing LOS). Existing LOS' indicates the current conditions of travel time and traffic intensity from field data. "Desired LOS" is the most achievable and awaited LOS. Since LOS A, B can't be achieved, and the toll price is really high. Alternative routes can therefore be congested. Due to the competitive method forecast, first calculated toll prices of LOS can be altered in a short space of time because of price changes in demand. It is easier to infer a value for the first test by use of the LOS relation than randomly. For the known segment length, the optimal average travel speed can be determined from the desired value. An inquiry may still locate actual traffic volumes, but the scientific evidence for the first trial can conclude that the target amount of traffic. Following this concept Equation (2) can be modified as

$$
\mathrm{CT}=\left[\frac{\left(T_{w, \text { existing }}-T_{w, \text { desired }}\right) \delta_{w} \omega}{X_{\text {existing }}-X_{\text {desired }}}+\frac{\left(T_{m, \text { existing }}-T_{m, \text { desired }}\right) \delta_{m} \omega}{X_{\text {existing }}-X_{\text {desired }}}\right] x
$$

where,

existing $=$ condition at existing LOS; desired $=$ condition at desired LOS. The rest of the parameters remain the same.

Using "Equation (3)" congestion toll for each segment can be estimated where the traffic flow is equal to the desired traffic flow $\left(x=x_{\text {desired }}\right)$.

The fact that the congest toll calculated with Equation (2) does not guarantee that LOS is exactly as desired, though, may be seen to increase LOS certainly given the facts of other countries. Upon having defined the estimated toll, more 
optimum congestion toll values can be found from the effect of the pricing. Congestion pricing itself is a form of research and error, and after daily traffic demand and supply, review modifications are taken. As regards the secondary data, the optimum congestion fee can only be given by the adjustment in traffic movement (noted $\mathrm{x}$ in Equation (2)), since the key objective of congestion pricing is to demand control. If private car counts do not reduce the congestion levels at the planned amount, then the next change would immediately raise. Likewise, the price would drop if the counts of private cars dip below the allowed amount of congestion.

\section{The Case Study}

Primary data is gathered during three working days a week in August 2019 from the field survey for this report. The volume count was calculated at the time of the peak hour (7:30 to 9:30am) from Sunday for a total of four outlets (Figure 2 ). For the total traffic volume value referring to segment 1 and segment 2, volume counts at stations 1 and 2 and 3 and 4 are considered. Noteworthy to say that access points add even less at peak hours to the traffic level of the two chosen segments.

The total amount of traffic in the entire segment is 698 vehicles per hour for Segment 1 and 652 vehicles per hour for Segment 2. However, if the metro service is open, these values are not the values of traffic volume. Therefore, it is appropriate to adjust the traffic value of segments 1 and 2 . Since the only public transit accessible in those segments today is bus service, the amount of bus traffic from the existing volume of traffic, provided the passengers of these busses are transferred to metro if the service is operating, is deducted from the current volume of traffic. The adjusted volume of segment 1 and segment 2 is according to this definition, respectively $515 \mathrm{veh} / \mathrm{hr} /$ lane and $458 \mathrm{veh} / \mathrm{lane}$.

For travel time data, three private cars (passenger car unit) were used to drive in both segments starting from Mirpur 10 Intersection up to Bijoy Sarani Intersection in three weekdays during peak hours (7:30-9:30AM). The travel time at the moving state for each segment was recorded separately.

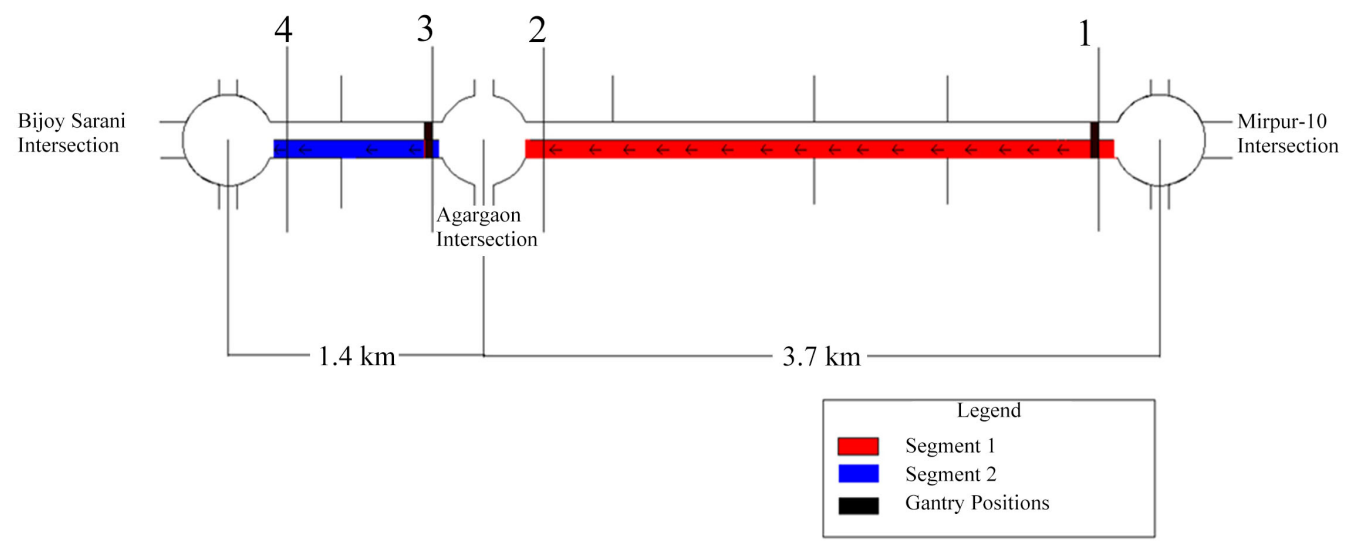

Figure 2. Volume count stations. 
The waiting time at Agargaon Intersection and Bijoy Sarani Intersection were also taken all three days which was the red time for the vehicles moving towards Bijoy Sarani from Mirpur 10. The average travel time at moving state for segment 1 is found 33 mins. $9 \mathrm{~s}$ and for segment 2 the value is 8 mins. $57 \mathrm{~s}$. The average waiting time at Agargaon Intersection and Bijoy Sarani Intersection are respectively 2 mins. $29 \mathrm{~s}$ and 2 mins. $47 \mathrm{~s}$.

Now, it is possible to check the existing vehicle LOS at both segment 1 and segment 2 consisting of $3.7 \mathrm{~km}$ and 1.4 respectively using the moving state travel time. By simple arithmetic calculation, the average travel speed at segment 1 is found $4.17 \mathrm{mi} / \mathrm{hr}$ and for segment 2 the value is $5.83 \mathrm{mi} / \mathrm{hr}$. For average travel speed of $4.17 \mathrm{mi} / \mathrm{hr}$ with calculated based free-flow speed $50 \mathrm{mi} / \mathrm{hr}$ and volume to capacity ratio 0.95 consulting Table 1 LOS at segment 1 is found F. Similarly, for an average travel speed of $5.83 \mathrm{mi} / \mathrm{hr}$ with same base free-flow speed and volume to capacity ratio of $0.80 \mathrm{LOS}$ is also $\mathrm{F}$ for segment 2 . As the waiting time at both intersections is greater than $80 \mathrm{~s}$, consulting Table 2 the LOS at both intersections can be declared F.

Table 1. LOS Criteria for motorized vehicle mode (source: Urban street segments, HCM2016).

\begin{tabular}{|c|c|c|c|c|c|c|c|c|}
\hline \multirow{2}{*}{ LOS } & \multicolumn{7}{|c|}{ Travel Speed Threshold by Base Free-Flow Speed (mi/h) } & \multirow{2}{*}{$\begin{array}{c}\text { Volume-to-Capacity } \\
\text { Ratio }\end{array}$} \\
\hline & 55 & 50 & 45 & 40 & 35 & 30 & 25 & \\
\hline A & $>44$ & $>40$ & $>36$ & $>32$ & $>28$ & $>24$ & $>20$ & \multirow{6}{*}{$\leq 1.0$} \\
\hline B & $>37$ & $>34$ & $>30$ & $>27$ & $>23$ & $>20$ & $>17$ & \\
\hline $\mathrm{C}$ & $>28$ & $>25$ & $>23$ & $>20$ & $>18$ & $>15$ & $>13$ & \\
\hline $\mathrm{D}$ & $>22$ & $>20$ & $>18$ & $>16$ & $>14$ & $>12$ & $>10$ & \\
\hline $\mathrm{E}$ & $>17$ & $>15$ & $>14$ & $>12$ & $>11$ & $>9$ & $>8$ & \\
\hline $\mathrm{F}$ & $\leq 17$ & $\leq 15$ & $\leq 14$ & $\leq 12$ & $\leq 11$ & $\leq 9$ & $\leq 8$ & \\
\hline F & & & & Any & & & & $>1.0$ \\
\hline
\end{tabular}

Note: Volume-to-Capacity Ratio of through movement at downstream boundary intersection.

Table 2. LOS criteria for motorized vehicle mode at a signalized intersection (Signalized Intersections, HCM-2016).

\begin{tabular}{ccc}
\hline & \multicolumn{2}{c}{ LOS by Volume-to-Capacity Ratio } \\
\cline { 2 - 3 } Control Delay (s/veh) & $\leq 1.0$ & \multicolumn{1}{c}{.1.0 } \\
\hline 10 & A & F \\
$>10-20$ & B & F \\
$>20-35$ & C & F \\
$>35-55$ & D & F \\
$>55-80$ & E & F \\
$>80$ & F & F \\
\hline
\end{tabular}


However, the price of congestion can be expected for a higher LOS as the scale of traffic reduces and thus increases the speed and the wait. While congestion costs prevent the usage of private cars, the private vehicles are not on the loser's side. In reality, in exchange for congestion, LOS is getting stronger. However, it will not be reasonable to predict congestion prices that desire a decent LOS, provided the present traffic conditions. Therefore, the desired LOS is believed to be C for both segments and crossings.

Now consulting Table 1 minimum average travel speed for achieving LOS C $(25 \mathrm{mi} / \mathrm{hr})$ is considered as desired travel speed and consulting Table 2 maximum waiting time allowable for LOS C (35 s) is considered as desired to wait time at both intersections. So, the calculated travel time is 5 mins $31 \mathrm{~s}$ for segment 1 and 2 mins. $2 \mathrm{~s}$ for segment 2 .

It is difficult to predict how much the traffic volume will reduce due to congestion pricing. However, a certain level of traffic volume can be expected to reduce considering the empirical evidence in other countries. As mentioned in section 2 Singapore's traffic volume during the non-ALS period and ALS period were found $600 \mathrm{veh} / \mathrm{hr} / \mathrm{lane}$ and $450 \mathrm{veh} / \mathrm{hr} / \mathrm{lane}$ where the traffic volume reduced to three-fourth due to congestion pricing. Therefore, the traffic volumes at segment 1 and segment 2 at desired LOS are assumed $386 \mathrm{veh} / \mathrm{hr} / \mathrm{lane}$ and 344 $\mathrm{veh} / \mathrm{hr} / \mathrm{lane}$ which are three-fourth of their current traffic volume. All moving time and waiting time data, traffic volume data are summarized in Table 3.

Substituting travel time and waiting time values in the unit of an hour and the traffic volume in the unit of veh/hr/lane in Equation (3) two expressions for two segments are obtained to estimate congestion toll for the private car. (passenger car unit).

$$
\begin{aligned}
& \mathrm{CT}_{1}=\left[\frac{\left(0.031667 \delta_{w}+0.460556 \delta_{m}\right) \omega}{129}\right] x \\
& \mathrm{CT}_{2}=\left[\frac{\left(0.036667 \delta_{w}+0.115278 \delta_{m}\right) \omega}{114}\right] x
\end{aligned}
$$

Table 3. Summary of travel time, waiting time, and traffic volume data.

\begin{tabular}{ccc}
\hline Data List & Segment 1 & Segment 2 \\
\hline Travel Time at moving state (min) & 33.15 & 8.95 \\
Existing LOS & 5.52 & 2.03 \\
Desired LOS & & \\
Waiting time at Intersections (s) & 149 & 167 \\
Existing LOS & 35 & 35 \\
Desired LOS & & \\
Traffic Volume (veh/hr/lane) & 515 & 458 \\
Existing LOS & 386 & 344 \\
Desired LOS &
\end{tabular}


Using these expressions congestion toll for any traffic level at the corresponding segment can be estimated.

For the value of $\omega$ (average wage rate) the average car owner's wage rate is more realistic to estimate congestion toll as it is mainly imposed on the private car. But due to the unavailability of any national census data for car owner's wage 4 th-grade wage rate of the 8 th national pay scale of Bangladesh is considered as the average wage rate of car owners that is equal to $50,000 \mathrm{BDT} / \mathrm{month}$ (\$588.24) or $288 \mathrm{BDT} / \mathrm{hr}(\$ 3.39 / \mathrm{hr})$ [14].

In a study, Khan \& Islam (2013) used a value of $80 \mathrm{BDT} / \mathrm{hr}(\$ 0.94)$ as the value of time for the car during peak hours in Dhaka city. This value the value of time is $28 \%$ of the average car owner's wage rate used in this study $(80 / 288=$ $0.28)$. Hence, as a base case, the congestion toll can be estimated for the combination $\left(\delta_{w}, \delta_{m}\right)=(0.28,0.28)$. But as the drivers value the waiting time at intersections more than the moving time [8] in his study regarding Singapore's ALS used $\delta_{\mathrm{w}}=0.75$ quite arbitrarily to capture the fact that $\delta_{w}$ is generally greater than $\delta_{m}$. In Bangladesh, there is no record of separate data for the value of waiting time and moving time. So, in this study a pair of $\left(\delta_{w}, \delta_{m}\right)=(0.75,0.28)$ is considered as the second case to estimate toll because this concept is an important part of the methodology.

Now substituting the values of $\omega$ in the unit of BDT/hr and $\left(\delta_{w}, \delta_{m}\right)$ in those expressions' congestion toll for a private car can be estimated for desired traffic flow which is $386 \mathrm{veh} / \mathrm{hr} /$ lane for segment 1 and $344 \mathrm{veh} / \mathrm{hr} /$ lane for segment 2 . Therefore, in the base case $\left(\delta_{w}, \delta_{m}\right)=(0.28,0.28)$ congestion toll is estimated 119 BDT (\$1.4) and 37 BDT (\$0.44) for segment 1 and segment 2 respectively. Congestion toll in the second case $\left(\delta_{w}, \delta_{m}\right)=(0.75,0.28)$ are $132 \mathrm{BDT}(\$ 1.55)$ for segment 1 and $52 \mathrm{BDT}(\$ 0.61)$ for segment 2. The overall toll charge is between $\$ 0.3$ - \$0.44 per private vehicle. Between these two cases, estimated toll values in the base case are more realistic because there may lie a significant difference in how waiting time is valued in Singapore and Bangladesh as the economic condition of people in these two countries differs a lot. The estimated charge will vary in peak \& off-peak hours, weekdays and weekend as the traffic volume fluctuate every time.

\section{Conclusions and Recommendation}

This paper develops a congestion price scope in Dhaka City; however, congestion pricing in Bangladesh has not been enforced. The results show affordable road pricing after the modified methodology is implemented where the original method is developed in Singapore. Most notably, the approach needs relatively minimal primary information. It is necessary to change the congestion toll by adjusting the traffic pattern. This study can seem early since the Metro Rail Service is not yet operating; however, there is a lack of data on the price of congestion in the Dhaka Area, such as the prices of time or average car owner's salary and other difficulties. This analysis incorporates certain conclusions that more 
reliable values may be derived from. Using revised data in the future using the same approach following the commencement of the metro rail services is necessary. Since, congestion prices have some political aspects, even if the government does not use this congestion price process, it may be enforced temporarily following this study by the government to verify congestion price acceptance level in Bangladesh.

A few more considerations, such as public acceptance, need to be discussed in depth before congestion pricing is implemented. An evaluation will help to determine whether the price is satisfactory or not before and during the trial. The automated toll scheme can also be used to reduce the vehicle queue at the segment entry stage. When the car moves through the gantry, it will retrieve money through DSRC or infrared technology from the transponder fitted to a dashboard, and the amount will be pre-loaded inside it. Before launching the service, the Gantry location should be set. The category of automobile that is exempted by the price scheme is necessary to repair. Emergency cars, such as ambulances, fire, police, municipal buses, minibuses, other vehicles such as freight transport and bicycles, are excluded from the toll scheme in the implemented cities (FHWA, 2008).

It can be hoped that in the future the government will introduce a Pricing Division in Dhaka town not only to minimize congestion but also optimize riding in MRT. In this study, only passenger cars and through movement traffic were considered for congestion pricing. Also, a few more limitations should be addressed such as traffic amount after MRT- 6 and wage amount. Further study is necessary to come up with a concrete pricing amount. Future studies should include road pricing based on different vehicle types, area type, traffic operation timing, as well as impact of the prices on users, travel behavior, the impact of air quality, space mean speed, and trip number on pricing implemented area.

\section{Acknowledgements}

The authors are grateful to Tanay Datta Chowdhury, Muntahith Mehadil Orvin and Md. Anwar Uddin for their assistance.

\section{Conflicts of Interest}

The authors declare no conflicts of interest regarding the publication of this paper.

\section{References}

[1] FHWA (2008) Lessons Learned from International Experience in Congestion Pricing. USDOT.

[2] Leitmann, J. (1999) Integrating the Environment in Urban Development: Singapore as a Model of Good Practice. World Bank.

[3] TfL (2005) Central London Congestion Charging Impact Monitoring. Mayor of London, London.

[4] Hugosson, M.B. and Eliasson, J. (2006) The Stockholm Congestion Charging Sys- 
tem-An Overview of the Effects After Six Months. Association for European Transport and Contributors, Stockholm.

[5] Peach, J. (2011) The Success of Stockholm's Congestion Pricing Solution. http://thisbigcity.net/the-success-of-stockholms-congestion-pricing-solution/

[6] DMTCL (2021).

http://dmtcl.portal.gov.bd/sites/default/files/files/dmtcl.portal.gov.bd/page/1e55ee4 $928914 \mathrm{c} 82$ b439 1e81df4d6cf7/2021-02-04-15-00-9e42c6a6a8f264a9911526039f3 61c43.pdf

[7] Hasnat, M.M. and Hoque, M.S. (2014) Reducing Congestion in Dhanmondi Residential Area: Introducing Cordon Pricing. International Journal of Advanced Engineering Research and Science, 1, 49-57.

[8] Li, M.Z.F. (1999) Estimating Congestion Toll by Using Traffic Count Data-Singapore's area Licensing Scheme. Transportation Research Part E, 35, 1-10. https://doi.org/10.1016/S1366-5545(98)00019-2

[9] Toh, R.S. (2004) Road Congestion Pricing in Singapore: 1975-2003. Transportation Journal, 43, 16-25.

[10] McCarthy, P.S. and Tay, R. (1993) Pricing Road Congestion: Recent Evidence from Singapore. Policy Studies Journal, 12, 296-308. https://doi.org/10.1111/j.1541-0072.1993.tb01823.x

[11] Bakkarsiddique, A., Mondal, P.K. and Choudhury, C.F. (2013) Investigating the Potential Presence to Congestion Pricing. 13th World Conference on Transport Research, Rio De Janerio.

[12] Khan, T. and Islam, M.R. (2013) Estimating Cost of Traffic Congestion in Dhaka City. International Journal of Engineering Science and Innovative Technology, 2, 281-289.

[13] HCM (2016) Highway Capacity Manual. TRB.

[14] Dteletalk, B. (2020) National Pay Scale 2015, Govt Job Salary Grade in Bangladesh. https://bdteletalk.com/national-pay-scale-govt-job-salary-grade/ 